\title{
Susceptibility of Liver Proliferative Lesions in Heterozygous p53 Deficient CBA Mice to Various Carcinogens
}

\author{
Takeki UEHARA $^{1)}$, Yoko KASHIDA ${ }^{1)}$, Takao WATANABE ${ }^{1)}$, Kazuo YASUHARA ${ }^{2)}$, Hiroshi ONODERA ${ }^{2)}$, \\ Masao HIROSE ${ }^{2)}$ and Kunitoshi MITSUMORI ${ }^{1,2) *}$ \\ ${ }^{1)}$ Laboratory of Veterinary Pathology, Tokyo University of Agriculture and Technology, 3-5-8, Saiwai-cho, Fuchu, Tokyo 183-8509 and \\ ${ }^{2)}$ Division of Pathology, National Institute of Health Sciences, 1-18-1 Kamiyoga, Setagaya-ku, Tokyo 158-8501, Japan
}

(Received 1 November 2001/Accepted 14 March 2002)

ABSTRACT. To investigate the liver tumorigenic sensitivity to various carcinogens in heterozygous $p 53$ deficient $[p 53(+/-)]$ CBA mice and their wild-type littermates [p53 (+/+) mice], 71 p53 (+/-) and 74 p53 (+/+) CBA mice (male, 6-12 weeks of age) were given diet containing 4,000 or $0 \mathrm{ppm}$ flumequine (FL) for 26 weeks or a single intraperitoneal injection of $5 \mathrm{mg} / \mathrm{kg}$ body weights dimethylnitros amine (DMN) at start of the study in Exp. 1, diet containing 6,000 or 0 ppm di(2-ethylhexyl)-phthalate (DEHP) for 26 weeks in Exp. 2, or diet containing 12,000, 6,000 or 0 ppm phenolphthalein $(\mathrm{PhP})$ for 26 weeks in Exp. 3. All surviving animals of these groups were killed after completion of treatment of the test substances for 26 weeks. In the FL groups, the incidences of hepatocellular altered foci in $p 53$ $(+/-)$ mice, the multiplicities of those in $p 53(+/-)$ and $p 53(+/+)$ mice were significantly increased as compared to the corresponding control groups. The incidences and multiplicities of altered foci in the DMN groups were higher than those in the corresponding control groups in $p 53(+/-)$ and $p 53(+/+)$ mice, but no significant differences were indicated between the groups. There were no significant differences in the incidences, multiplicities and proliferating cell nuclear antigen labeling indices of altered foci in the FLor DMN groups between $p 53(+/-)$ and $p 53(+/+)$ mice. There were no significant differences in the incidences and multiplicities of altered foci between the DEHP or PhP and control groups. The present results suggest that $p 53$ gene knocked out heterozygously does not enhance the chemical hepatocarcinogenesis in CBA mice.

KEY WORDS: dimethylnitrosamine, di(2-ethylhexyl)-phthalate, flumequine, phenolphthalein, p53 (+/-) CBA mouse.

J. Vet. Med. Sci. 64(7): 551-556, 2002

Recently, the utility of genetically altered mice in carcinogenicity studies with short-term treatment period of less than 6 months has been investigated on a global scale. In particular, heterozygous $p 53$ deficient $[p 53(+/-)]$ mice, in which the lateral allele of $p 53$ gene is inactivated, have received much attention in detection of the carcinogenic potential of genotoxic carcinogens with high sensitivity [18]. It is known that $p 53$ gene is one of the tumor suppressor genes, acting as a regulator of cell cycle and apoptosis [5]. In addition, loss and/or mutations of p53 gene have been associated with spontaneously occurring various human malignant tumors [10].

Currently, two different strains of p53 (+/-) mice are available in Japan. One is p53 (+/-) TSG mice (Taconic Farms, Germantown, U.S.A.), p53 (+/-) C57BL/6 mice background, in which exon 5 of the lateral $p 53$ allele was inactivated. The other is p53 (+/-) CBA mice (Oriental Yeast Co., Tokyo, Japan) in which exon 2 of the lateral p53 allele was inactivated, and they are F1 offspring of heterozygous p53 deficient C57BL/6J male mice back-crossed with CBA female mice [19]. A considerable number of reports concerned with p53 (+/-) TSG mice have previously been published, demonstrating that this model has high sensitivity to genotoxic carcinogens [9]. However, other studies have demonstrated that there were no significant differences in the rate of development of diethylnitrosamine (DEN)-

\footnotetext{
* Correspondence to: Mitsumori, K., Laboratory of Veterinary Pathology, Tokyo University of Agriculture and Technology, 35-8 Saiwai-cho, Fuchu, Tokyo 183-8509, Japan.
}

induced hepatocellular proliferating lesions between $p 53(+/$ -) and p53(+/+) TSG mice [11]. Furthermore, dimethylnitrosamine (DMN) treatment to newly born p53 (+/-) TSG mice produced liver tumors at lower incidences than those of $p 53(+/+)$ TSG mice [3]. These findings suggest that $p 53$ (+/-) TSG mice exhibit low sensitivity to chemical hepatocarcinogenesis. On the other hand, in our previous study using p53 (+/-) CBA mice, treatment of phenobarbital (PB) after DMN-initiation produced liver tumors with a high frequency [15]. These results indicate that the sensitivity of p53 (+/-) TSG mice to hepatocarcinogens is different from that of p53 (+/-) CBA mice. However, no other studies on the hepatocarcinogenic sensitivity of $p 53(+/-)$ CBA mice have been reported in the literature. Therefore, in the present study, we investigated the hepatocarcinogenic sensitivity of p53 (+/-) CBA mice to various carcinogens, such as flumequine (FL) that is a fluoroquinolone-antimicrobial agent and suspected to be a genotoxic hepatocarcinogen, $\mathrm{DMN}$ that is a representative genotoxic hepatocarcinogen, di(2-ethylhexyl)-phthalate (DEHP) that is a typical nongenotoxic hepatocarcinogen, and phenolphthalein (PhP) that is a genotoxic carcinogen targeting organs other than the liver.

\section{MATERIALS AND METHODS}

Test substance: FL was obtained as a gift from Kyowa Hakko Kogyo (Tokyo, Japan). DEHP and PhP were purchased from Wako Pure Chemicals Industries, Ltd. (Osaka, 
Japan). DMN obtained from Nacarai Tesque Inc. (Kyoto, Japan) was dissolved in saline and passed through a membrane filter with $0.22 \mu \mathrm{m}$ pore size (MILLEX-GV, Japan Millipore Ltd., Tokyo Japan) just before usage.

Experimental animals: Seventy one male heterozygous p53 deficient CBA mice [p53 (+/-) mice] and 74 male their wild-type littermates $[p 53(+/+)$ mice] were purchased from Oriental Yeast Co. (Tokyo, Japan). The present study consisted of different three experiments (Exp. 1, 2 and 3) that were performed separately, since the birth rate of these animals was extremely low and a large numbers of mice could not be obtained at the same time. The animals used in Exps. 1, 2 and 3 were 9-10, 6-8 and 11-12 weeks of age, respectively, at start of the study. They were housed at a maximum of 5 per cage in plastic cages with soft chip bedding in a room that was controlled light-dark cycle (12-12 hr, lights on 7:00-19:00), ventilation (air-exchange rate of 18 times per hour), temperature $\left(21-25^{\circ} \mathrm{C}\right)$ and relative humidity (50-60\%) during the study. Each animal had free access to powdered basal diet $\left(\mathrm{CRF}-1^{\circledR}\right.$, Oriental Yeast Co.) and tap water.

Experimental design: In Exp. 1, p53 (+/-) and p53 (+/+) mice of the DMN (6 animals each) or FL (15 animals each) groups received a single intraperitoneal injection of DMN at $5 \mathrm{mg} / \mathrm{kg}$ body weight at start of the study or were fed powdered diet (CRF-1(r)) containing 4,000 ppm FL for 26 weeks, respectively. The remaining 5 p53 (+/-) mice and 6 p53 (+/+) mice were served as the control. This experiment was a part of our previous study in which initiating activities of flumequine were investigated in $p 53(+/-)$ CBA mice [17]. In Exp. 2, 9 p53 (+/-) and 11 p53 (+/+) mice of the DEHP or 9 p $53(+/-)$ mice and 8 p53 (+/+) mice of the control groups were maintained with a powdered $\operatorname{diet}\left(\mathrm{CRF}-1^{\circledR}\right)$ containing 6,000 ppm DEHP or powdered basal diet for 26 weeks, respectively. In Exp. 3, p53 (+/-) mice and p53 (+/+) mice were fed powdered diet (CRF-1(r)) containing 12,000, 6,000 or $0 \mathrm{ppm} \mathrm{PhP}$ for 26 weeks. The numbers of animals used in the $12,000,6,000$ or 0 ppm group were 10,10 or 7 in p53 (+/-) mice and 10,10 or 8 in p53 (+/+) mice, respectively. The powdered diet was freshly prepared every week during the treatment period.

Histopathological examination: Animals that died during the experimental period were subjected to a complete necropsy as soon as they were found. All surviving animals were sacrificed under ether anesthesia and necropsied. A wide variety of organs and tissues including the liver were fixed in $10 \%$ neutral buffered formalin. The liver tissues were processed routinely, embedded in paraffin, sectioned at 4-5 $\mu \mathrm{m}$, and stained with hematoxylin and eosin (H\&E) for microscopic examinations. Furthermore, liver sections of the groups subjected to FL or DMN treatment were immunohistochemically stained for proliferating cell nuclear antigen (PCNA) using an anti-PCNA mouse monoclonal antibody (DAKO, Glostrup, Denmark) at dilutions of 1:100 and avidin-biotin peroxidase complex kits (Burlingame, CA, U.S.A.) with a chromogen of 3, 3'-diaminobenzidine followed by counterstaining with hematoxylin. The number of PCNA positive cells per over 50 cells in each proliferative lesion was counted from 2-5 different areas. The PCNA labeling index (PCNA LI) was calculated as percentage of positive cells to 100 cells forming each proliferative lesion.

Statistical analysis: The incidences of liver proliferative lesions were analyzed by Fisher's exact test. The multiplicities and PCNA LIs were expressed as mean \pm standard deviation (SD), and analyzed by Welch's method or Student's $t$-test. Significant difference between the treated group and corresponding control group, or between treated p53 (+/-) and p53 (+/+) mice was assessed. Results were considered as significant where the $\mathrm{p}$ value was less than 0.05 .

\section{RESULTS}

Exp. 1: Three $p 53(+/-)$ and 1 p53 (+/+) mice receiving FL died due to the treatment-related hepatotoxic injuries (Table 1). One p53 (+/-) mouse in the control group also died of a malignant lymphoma. There were no liver tumors in all surviving mice of both p53 (+/-) and p53 (+/+) mice treated with FL or DMN. The incidences (multiplicities) of hepatocellular altered foci in p53 (+/-) and p $53(+/+)$ mice were $100 \%(34.6 \pm 20.5)$ and $100 \%(31.9 \pm 13.7)$ in the FL groups, $66.7 \%(1.0 \pm 0.9)$ and $83.3 \%(2.2 \pm 1.9)$ in the DMN groups, and $50 \%(0.5 \pm 0.6)$ and $33.3 \%(0.3 \pm 0.5)$ in the control groups, respectively. The incidence of altered foci in the FL group was significantly higher than that in the control group of $p 53(+/+)$ mice $(\mathrm{p}<0.005)$. The multiplicities of altered foci in the FL groups were significantly increased as compared to the corresponding control groups in p53 (+/ -) and $p 53(+/+)$ mice $(p<0.001)$. The incidences and multiplicities of altered foci in the DMN groups were higher than those in the corresponding control groups in p53 (+/-) and p53 (+/+) mice, without any significant difference (Fig. 1). Phenotypes of altered foci were predominantly clear cell type in the FL groups, whereas almost all altered foci in the DMN and control groups were basophilic cell type (Fig. 2). The PCNA LIs of altered foci in p53 (+/-) and p53 (+/+) mice were $5.56 \pm 3.95$ and $5.14 \pm 2.97$ in the FL groups, and $2.96 \pm 2.75$ and $1.55 \pm 0.95$ in the DMN groups, respectively. There were no significant differences between $p 53$ (+/-) and $p 53(+/+)$ mice of the FL or DMN groups (Fig. 3).

Exp. 2: One p53 (+/-) and 1 p53 (+/+) mice in the DEHP group died of a malignant lymphoma and pyelonephritis during the study, respectively. There was no obvious adverse effect related to the treatment of DEHP that affected overall survival rates (Table 1). No liver tumors were observed in all mice regardless of the treatment, except for one $p 53(+/-)$ mouse in the control group in which a hepatocellular adenoma was observed. The livers of all DEHPtreated $p 53(+/-)$ and $p 53(+/+)$ mice exhibited moderate to marked centrilobular hepatocellular hypertrophy. The incidences (multiplicities) of hepatocellular altered foci were $37.5 \%(0.4 \pm 0.5)$ in $p 53(+/-)$ mice and $10.0 \%(0.1 \pm 0.3)$ in p53 (+/+) mice treated with DEHP, and their incidences and 
Table 1. Survival rate and the numbers of animals used for histopathological examinations in $p 53(+/-)$ and $p 53(+/+)$ mice treated with various carcinogens

\begin{tabular}{|c|c|c|c|c|c|c|c|c|c|c|c|c|c|c|c|c|}
\hline & \multicolumn{6}{|c|}{ Exp. 1} & \multicolumn{4}{|c|}{ Exp. 2} & \multicolumn{6}{|c|}{ Exp. 3} \\
\hline & \multicolumn{3}{|c|}{$p 53(+/-)$} & \multicolumn{3}{|c|}{$P 53(+/+)$} & \multicolumn{2}{|c|}{ P53 (+/-) } & \multicolumn{2}{|c|}{$P 53(+/+)$} & \multicolumn{3}{|c|}{ p53 (+/-) } & \multicolumn{3}{|c|}{$p 53(+/+)$} \\
\hline & Cont. & DMN & FL & Cont. & DMN & FL & Cont. & $\overline{\mathrm{DEHP}}$ & Cont. & $\overline{\text { DEHP }}$ & Cont. & $\mathrm{PhP}^{\mathrm{a})}$ & $\overline{\mathrm{PhP}^{\mathrm{b})}}$ & Cont. & $\mathrm{PhP}^{\mathrm{a})}$ & $\mathrm{PhP}^{\mathrm{b})}$ \\
\hline $\begin{array}{l}\text { Survival rate } \\
\text { (percentage) }\end{array}$ & $\begin{array}{l}4 / 5 \\
(80)\end{array}$ & $\begin{array}{c}6 / 6 \\
(100)\end{array}$ & $\begin{array}{c}12 / 15 \\
(80)\end{array}$ & $\begin{array}{c}6 / 6 \\
(100)\end{array}$ & $\begin{array}{c}6 / 6 \\
(100)\end{array}$ & $\begin{array}{c}14 / 15 \\
(93)\end{array}$ & $\begin{array}{c}9 / 9 \\
(100)\end{array}$ & $\begin{array}{c}8 / 9 \\
(89)\end{array}$ & $\begin{array}{c}8 / 8 \\
(100)\end{array}$ & $\begin{array}{c}10 / 11 \\
(91)\end{array}$ & $\begin{array}{c}7 / 7 \\
(100)\end{array}$ & $\begin{array}{l}9 / 10 \\
(90)\end{array}$ & $\begin{array}{l}9 / 10 \\
(90)\end{array}$ & $\begin{array}{l}7 / 8 \\
(88)\end{array}$ & $\begin{array}{l}9 / 10 \\
(90)\end{array}$ & $\begin{array}{l}6 / 10 \\
(60)\end{array}$ \\
\hline $\begin{array}{c}\text { Number of } \\
\text { animals }^{\mathrm{c})}\end{array}$ & 4 & 6 & 11 & 6 & 6 & 14 & 9 & 8 & 8 & 10 & 3 & 8 & 9 & 7 & 9 & 6 \\
\hline
\end{tabular}

a) Group fed diet containing 6,000 ppm PhP. b) Group fed diet containing 12,000 ppm PhP. c) Number of animals used for histopathological examinations. Cont.: Control. DMN: Dimethylnitrosamine. FL: Flumequine. DEHP: Di (2-ethylhexyl)-phthalate. PhP: Phenolphthalein.
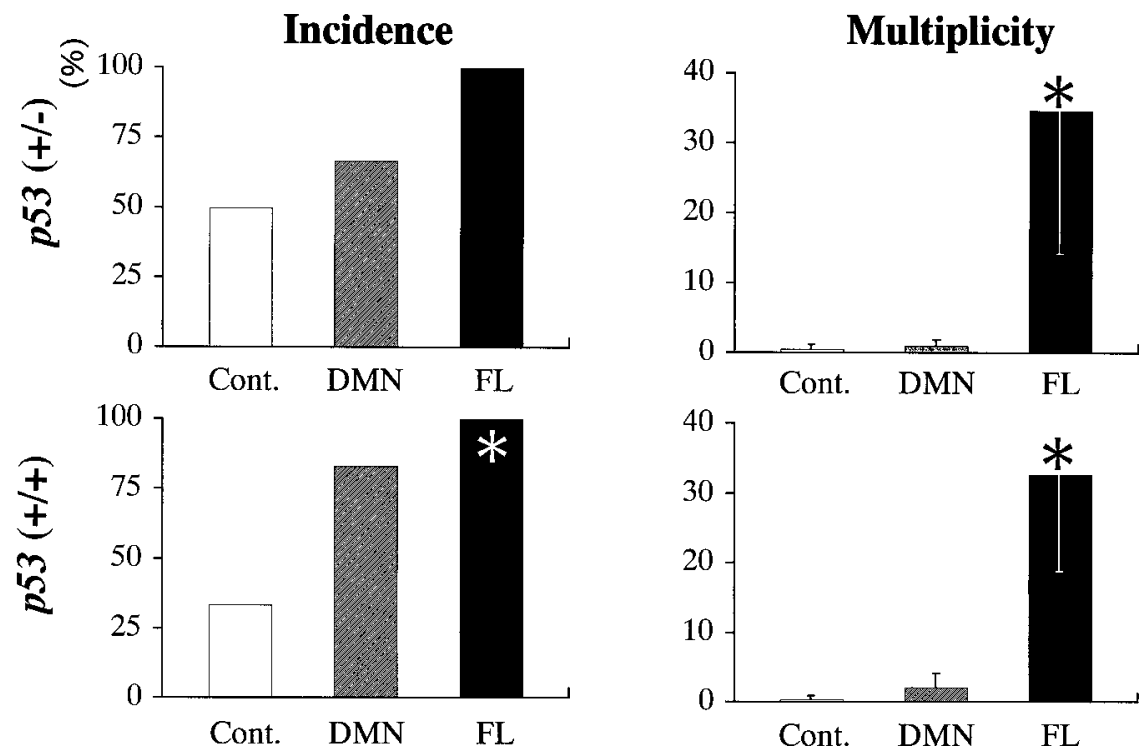

Fig. 1. Incidences and multiplicities of hepatocellular altered foci in $p 53(+/-)$ and $p 53(+/+)$ mice treated with FL or DMN. Data of multiplicities are expressed as mean \pm SD. *: Significantly different from the control group of $p 53(+/+)$ mice by Fisher's exact test $(p<0.005)$. \$: Significantly different from the corresponding control groups of $p 53(+/-)$ and $p 53(+/+)$ mice by Welch's method $(p<0.001)$. Cont.: Control. DMN: Dimethylnitrosamine. FL: Flumequine.

multiplicities were not significantly different from those in the corresponding control groups $[22.2 \%(0.2 \pm 0.4), 0 \%$ $(0.0 \pm 0.0)]$ (Fig. 4).

Exp. 3: One p53 (+/-) mouse receiving 12,000 ppm $\mathrm{PhP}$ died of a malignant lymphoma by end of the treatment. However, the cause of death in 4 p53 (+/+) mice receiving $12,000 \mathrm{ppm} \mathrm{PhP}$, and 1 p53 (+/-) and 1 p53 (+/+) mice receiving 6,000 $\mathrm{ppm} \mathrm{PhP}$ was not clarified due to advanced autolysis (Table 1). There were no liver tumors in all mice regardless of the treatment. The incidences (multiplicities) of hepatocellular altered foci in $p 53(+/-)$ and $p 53(+/+)$ mice were $22.2 \%(0.2 \pm 0.4)$ and $33.3 \%(0.5 \pm 0.8)$ in the 12,000 ppm groups, and $12.5 \%(0.1 \pm 0.4)$ and $0 \%(0.0 \pm 0.0)$ in the $6,000 \mathrm{ppm}$ groups, respectively. Their incidences and multiplicities were not significantly different from those in the corresponding control groups $[33.3 \%(0.7 \pm 1.2), 28.6 \%$ $(0.4 \pm 0.8)]$ (Fig. 5).

\section{DISCUSSION}

In the present study, unequivocal induction of neoplastic lesions of the liver was not apparent, but numerous hepatocellular altered foci were induced in p53 (+/-) and p53 (+/+) CBA mice treated with FL that had been negative in in vitro bacterial or mammalian cell gene mutation assays and in vivo chromosomal aberration test in bone-marrow cells of rats [20]. Yoshida et al. also reported that FL not only enhanced a development of altered foci and adenomas of the hepatocytes in CD-1 mice by dietary administration at 4,000 ppm FL for 30 weeks after an initiation of DEN, but also induced small numbers of altered foci at the same dose without any initiation treatment [21]. Based on these findings, the possibility that FL exerts a direct genotoxic effect on hepatocytes can not be ruled out. In this respect, FL is considered as a genotoxic hepatocarcinogen, but further experi- 

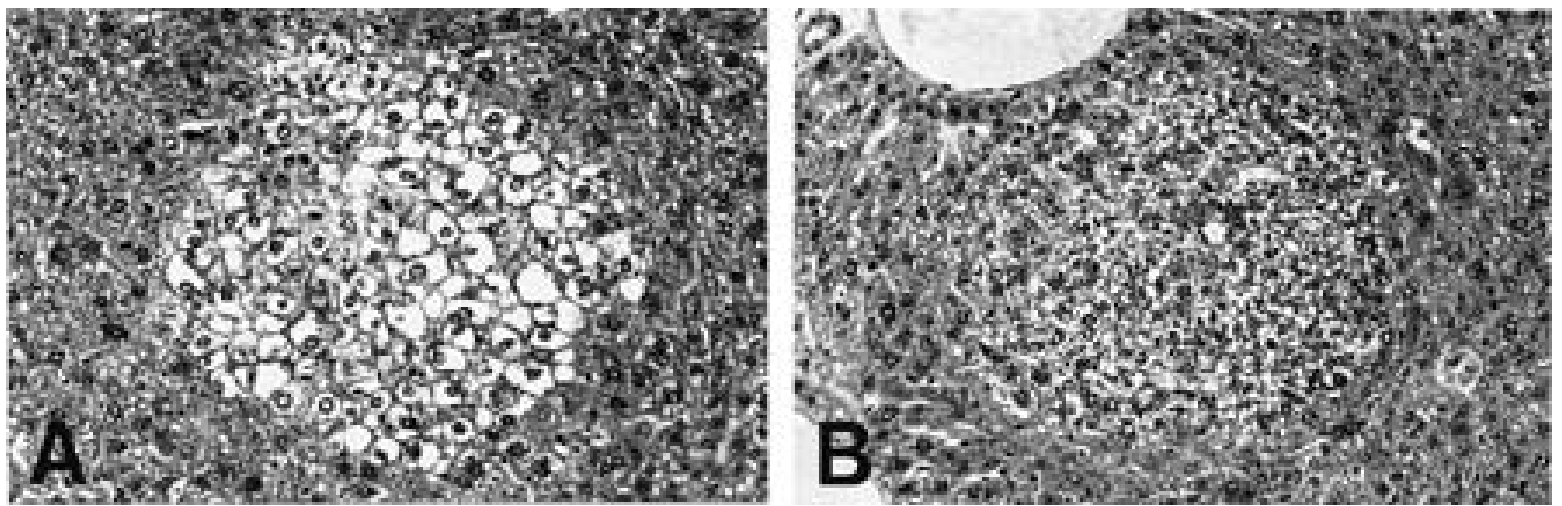

Fig. 2. Photomicrographs of hepatocellular altered foci in FL or DMN-treated mice. A) $p 53(+/-)$ mouse in the FL group. B) $p 53$ (+/+) mouse in the DMN group. H\&E. $\times 141$.

(\%)

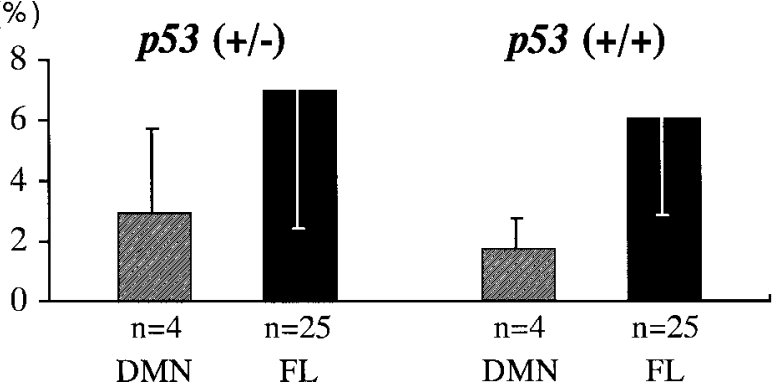

Fig. 3. PCNA LIs [ (Number of PCNA positive cells/100 cells forming hepatocellular altered foci) $\times 100$.] of hepatocellular altered foci in $p 53(+/-)$ and $p 53(+/+)$ mice treated with DMN or FL. Data are expressed as mean \pm SD. n: Number of lesions examined. DMN: Dimethylnitrosamine. FL: Flumequine.

ments addressing on genetic alteration will be necessary to elucidate the precise mechanism of the hepatocarcinogenicity of FL.

Although DMN is known to induce mutations of hepatocytes [1] and hepatocellular tumors in $\mathrm{C} 3 \mathrm{Hf}$ and Swiss mice $[4,8]$, DMN-treatment to $p 53(+/-)$ and $p 53(+/+)$ CBA mice did not induce any apparent hepatocellular tumors in the present study. However, the incidences and multiplicities of hepatocellular altered foci in the DMN groups were higher than those in the respective control groups in p53 (+/-) and p53 (+/+) CBA mice, but no significant differences were indicated between the groups. Therefore, although DMN is regarded to have an initiating effect to the liver of p53 (+/-) and $p 53(+/+)$ CBA mice, it is suggested that a single intraperitoneal injection of DMN used in our study is not sufficient to induce altered foci in the liver.

On the other hand, such hepatocellular proliferative lesions were not induced in p53 (+/-) and p53(+/+) CBA mice treated with DEHP or PhP in the present study. DEHP is known as one of the substances called peroxisome proliferators, which induce increased peroxisome formation and drug metabolizing enzyme activities in the livers of rats
[13]. In 1978, DEHP was found in two-year carcinogenicity bioassays performed in the National Toxicology Program (NTP) to be a hepatocarcinogen in Fischer 344 rats and $\mathrm{B} 6 \mathrm{C} 3 \mathrm{~F}_{1}$ mice [12]. In addition, clofibrate, that is also one of the peroxisome proliferators, is known to induce hepatocellular tumors in rats and mice [16]. Since it is known that clofibrate stimulates replicative DNA synthesis and cell division [2], it is assumed that the indirect DNA damage and some other promotional mechanism may be involved in its hepatocarcinogenesis. Therefore, peroxisome proliferators including DEHP have been recognized to induce hepatocellular tumors in rodents by a non-genotoxic pathway. The results of the present study suggests that $p 53(+/-)$ mice do not respond to non-genotoxic hepatocarcinogens, such as DEHP, since there was no apparent increase in the inicidences and multiplicities of hepatocellular altered foci in p53 (+/-) and p53 (+/+) CBA mice treated with DEHP.

$\mathrm{PhP}$, that was used as a laxative for most of the twentieth century, was carcinogenic to rats and mice in the 2-year studies, in which neoplasms in the kidney and adrenal medulla of male rats, hematopoietic tumors in male and female mice (histiocytic sarcomas and malignant lymphomas), and ovarian tumors of female mice were induced by the treatment of PhP [6]. In addition, PhP has been reported to be positive in chromosomal aberration test of cultured Chinese hamster ovary cells and micronucleus test of peripheral blood samples from mice [14]. Furthermore, malignant lymphomas of thymic origin were also induced in p53 (+/-) TSG mice by the treatment with PhP for 6 months [7]. However, PhP rarely induced hepatocellular proliferative lesions in $p 53(+/-)$ and $p 53(+/+)$ CBA mice in our study. Therefore, $\mathrm{PhP}$ is considered to be a genotoxic carcinogen targeting organs other than the liver.

In conclusion, hepatocellular altered foci were induced in p53 (+/+) as well as p53 (+/-) CBA mice treated with genotoxic hepatocarcinogens in the present study irrespective of short-term treatment period of less than 6 months. However, the PCNA LIs as well as the incidences and multiplicities of altered foci in p53 (+/-) CBA mice of the FL and 

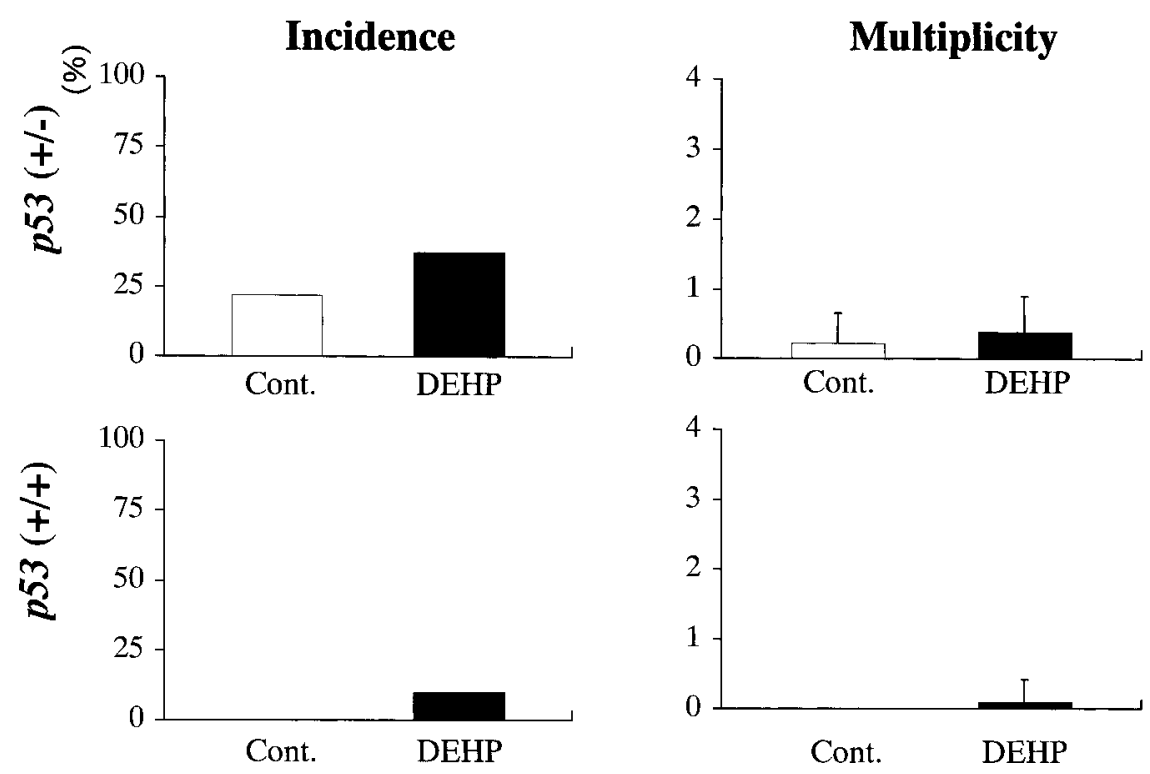

Fig. 4. Incidences and multiplicities of hepatocellular altered foci in $p 53(+/-)$ and $p 53(+/+)$ mice treated with DEHP. Data of multiplicities are expressed as mean \pm SD. Cont.: Control. DEHP: $\operatorname{Di}(2$-ethylhexyl)-phthalate.
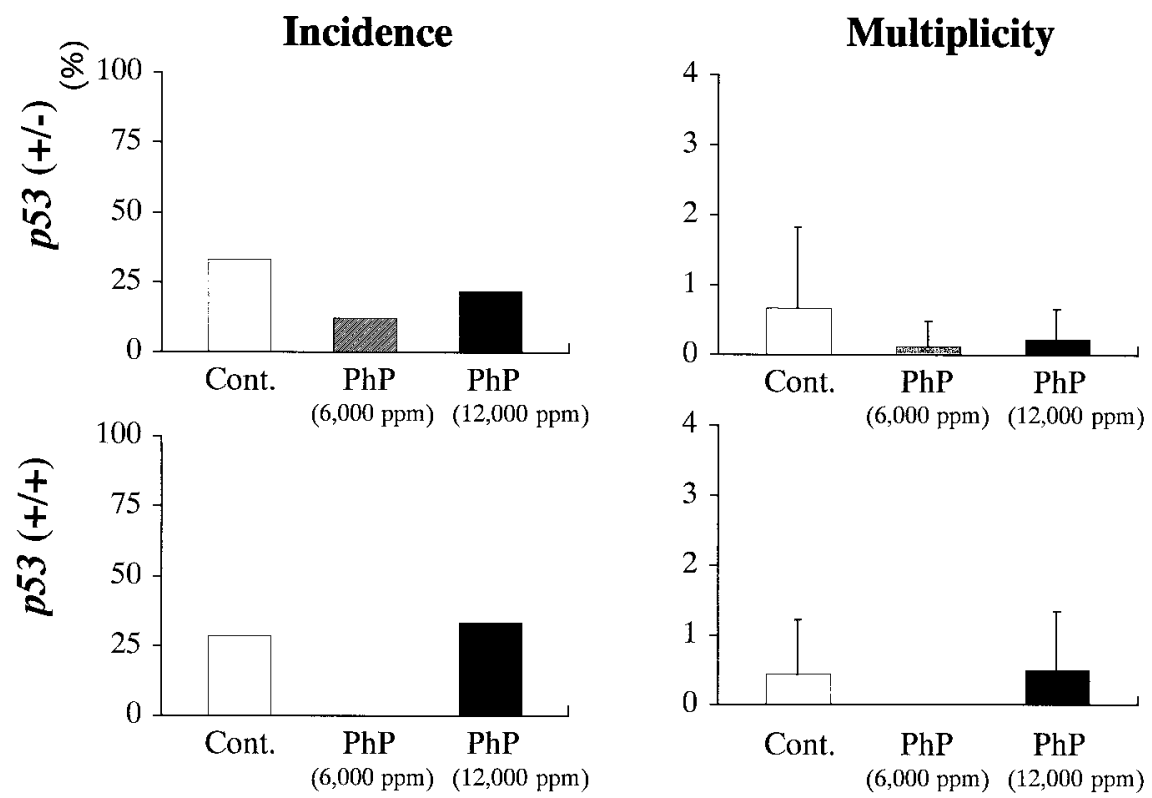

Fig. 5. Incidences and multiplicities of hepatocellular altered foci in $p 53(+/-)$ and $p 53(+/+)$ mice treated with PhP. Data of multiplicities are expressed as mean \pm SD. Cont.: Control. PhP: Phenolphthalein.

DMN groups were not different from those in $p 53(+/+)$ CBA mice of the same groups. These results suggest that p53 gene knocked out heterozygously does not enhance the chemical hepatocarcinogenesis in CBA mice. Therefore, when in selection of a genetically modified mouse to examine the carcinogenic potential of newly-developed chemi- cals, it should be taken into account that p53 (+/-) mice are not always susceptible to hepatocarcinogens.

ACKNOWLEDGEMENTS. This work was supported in part by Special Coordination Funds for Promoting Science and Technology of the Science and Technology Agency of 
Japan and a grant-in-aid from the Ministry of Education of Japan.

\section{REFERENCES}

1. Armato, U., Wu, J., Menegazzi, M., Menapace, L., Ribecco, M., Testolin, L., Carcereri De Prati, A. and Suzuki, H. 1993. The in utero initiation with DMN alters the complement of cytosolic glutathione S-transferases and the phenobarbitalinduced expression of c-jun and c-myc oncogenes in primary neonatal rat hepatocytes. Cytotechnology (Suppl. 1): S18-20.

2. Ashby, J., Brady, A., Elcombe, C. R., Elliott, B. M., Ishmael, J., Odum, J., Tugwood, J. D., Kettle, S. and Purchase, I. F. 1994. Mechanistically-based human hazard assessment of peroxisome proliferator-induced hepatocarcinogenesis. Hum. Exp. Toxicol. (Suppl. 2): S1-117.

3. Dass, S.B., Bucci, T.J., Heflich, R.H. and Casciano, D.A. 1999. Evaluation of the transgenic $p 53+/-$ mouse for detecting genotoxic liver carcinogens in a short-term bioassay. Cancer Letters 143: 81-85.

4. Engelse, L.D., Hollander, C. F. and Misdorp, W. 1974. A sexdependent difference in the type of tumours induced by dimethylnitrosamine in the livers of C3Hf mice. Eur. J. Cancer 10: 129-135.

5. Donehower, L. A. and Bradley, A. 1993. The tumor suppressor p53. Biochim. Biophys. Acta 1155: 181-205.

6. Dunnick, J. K. and Hailey, J. R. 1996. Phenolphthalein exposure causes multiple carcinogenic effects in experimental model systems. Cancer Res. 56: 4922-4926.

7. Dunnick, J. K., Hardisty, J. F., Herbert, R. A., Seely, J. C., Furedi-Machacek, E. M., Foley, J. F., Lacks, G. D., Stasiewicz, S. and French, J. E. 1997. Phenolphthalein induces thymic lymphomas accompanied by loss of the $p 53$ wild type allele in heterozygous p53-deficient (+/-) mice. Toxicol. Pathol. 25: 533-540.

8. Frei, J. V. 1970. Toxicity, tissue changes, and tumor induction in inbred Swiss mice by methylnitrosamine and -amide compounds. Cancer Res. 30: 11-17.

9. Harvey, M., McArthur, M. J., Montgomery, C. A., Butel, J. S., Bradley, A. and Donehower, L. A. 1993. Spontaneous and carcinogen-induced tumorigenesis in p53-deficient mice. Nat. Genet. 5: 225-229.

10. Hollstein, M., Sidransky, D., Vogelstein, B. and Harris, C. C. 1991. p53 mutations in human cancers. Science 253: 49-53.

11. Kemp, C. J. 1995. Hepatocarcinogenesis in $p 53$-deficient mice.
Mol. Carcinogenesis 12: 132-136.

12. Kluwe, W. M., Haseman, J. K., Douglas, J. F. and Huff, J. E. 1982. The carcinogenicity of dietary di(2-ethylhexyl) phthalate (DEHP) in Fischer 344 rats and B6C $3 F_{1}$ mice. J. Toxicol. Environ. Health. 10: 797-815.

13. Moody, D. E. and Reddy, J. K. 1978. Hepatic peroxisome (microbody) proliferation in rats fed plasticizers and related compounds. Toxicol. Appl. Pharmacol. 45: 497-504.

14. National Toxicology Program (NTP). 1996. Toxicology and carcinogenesis studies of phenolphthalein in F344/N rats and B6C3F1 mice (feed studies). NTP Technical Report No. 465, US Department of Health and Human Services, Public Health Service, National Institutes of Health, Bethesda.

15. Onodera, H., Mitsumori, K., Takagi, H., Yasuhara, K., Koujitani, T., Tamura, T. and Hirose, M. Susceptibility of liver proliferative lesions in heterozygous $p 53$ deficient CBA mice treated with phenobarbital after initiation of dimethylnitrosamine. J. Toxicol. Pathol. (in press)

16. Reddy, J. K. and Lalwai, N. D. 1983. Carcinogenesis by hepatic peroxisome proliferators: Evaluation of the risk of hypolipidemic drugs and industrial plasticizers to humans. Crit. Rev. Toxicol. 12: 1-58.

17. Takizawa, T., Mitsumori, K., Takagi, H., Onodera, H., Yasuhara, K., Tamura, T. and Hirose, M. 2001. Modifying effects of flumequine on dimethylnitrosamine-induced hepatocarcinogenesis in heterozygous $p 53$ deficient CBA mice. J. Toxicol. Pathol. 14: 135-143.

18. Tennant, R. W., Spalding, J. and French, J. E. 1996. Evaluation of transgenic mouse bioassays for identifying carcinogens and noncarcinogens. Mutation Res. 365: 119-127.

19. Tsukada, T., Tomooka, Y., Takai, S., Ueda, Y., Nishikawa, S., Yagi, T., Tokunaga, T., Takeda, N., Suda, Y., Abe, S., Matsuo, I., Ikawa, Y. and Aizawa, S. 1993. Enhanced proliferative potential in culture of cells from $p 53$-deficient mice. Oncogene 8: $3313-3322$

20. WHO. 1997. Toxicological evaluation of certain veterinary drugs residues in food. The forty-eighth meeting of the joint FAO/WHO expert committee on food additives (JECFA), WHO Food Additives Series 39: 63-75.

21. Yoshida, M., Miyajima, K., Shiraki, K., Ando, J., Kudoh K., Nakae, D., Takahashi, M. and Maekawa, A. 1999. Hepatotoxicity and consequently increased cell proliferation are associated with flumequine hepatocarcinogenesis in mice. Cancer Letters 141: 99-107. 